Federal Reserve Bank of Dallas

Globalization and Monetary Policy Institute

Working Paper No. 63

http://www.dallasfed.org/assets/documents/institute/wpapers/2010/0063.pdf

\title{
Export Shocks and the Zero Bound Trap*
}

Ippei Fujiwara

Bank of Japan

October 2010

\begin{abstract}
When a small open economy experiences a sufficiently large negative export shock, it is vulnerable to falling into a zero bound trap. In addition, such a shock can have very large impact on the economy compared to the case when the zero bound is not a binding constraint. This could be one possible explanation as to why a country like Japan experienced much larger drop in output than the United States during the recent financial crisis.
\end{abstract}

JEL codes: E52, E58, F41

\footnotetext{
* Ippei Fujiwara, Director, Financial Markets Department, Bank of Japan, 2-1-1 Nihonbashi-Hongokucho, Chuo-Ku, Tokyo 103-8660, Japan. Ippei.fujiwara@boj.or.jp. http://sites.google.com/site/ippeifujiwara. The author thanks Larry Christiano for sharing the analytical tools used in this paper and insightful discussions, especially at the onset of this research project. Thanks also go to Lena Körber and Maury Obstfeld for discussions and comments. The views in this paper are those of the author and do not necessarily reflect the views of the Bank of Japan, the Federal Reserve Bank of Dallas or the Federal Reserve System.
} 


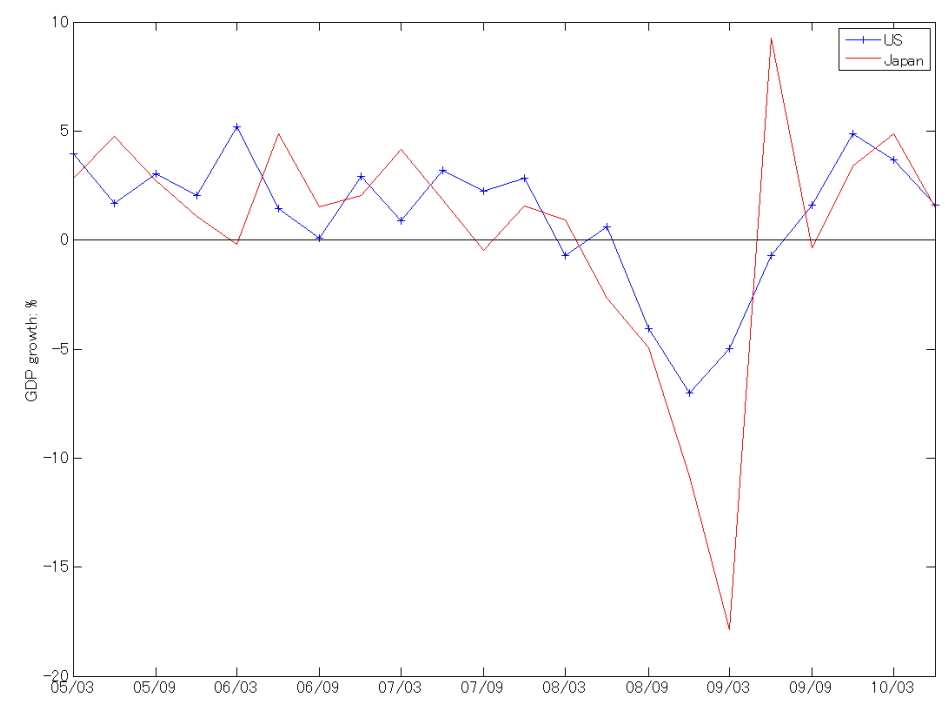

Figure 1: GDP Growth Rates: Japan and the U.S.

\section{Introduction}

During the midst of the recent financial crisis, many countries encountered a severe negative shock to output. Major countries have experienced a significant contraction in economic activity. Among them, the drop in Japan is notably outstanding. Figure 1 displays that the GDP growth rates in the 4th quarter of 2008 and the 1st quarter of 2009 are $-10.8 \%$ and $-17.9 \%$ respectively, while those in the United States, the origin country of the recent financial crisis, are $-7.0 \%$ and $-5.0 \%$. The fact that larger drop was observed in Japan is very intriguing, since Japan did not face domestic financial or economic problems, at least, more severe than the United States during this time. $^{1}$

Several thoughts have been raised to understand the global comovements of the output collapse during the financial crisis. For example, Caballero and Kurlat (2009) point out the possibility that the world became excessively avert to ambiguity reacting to the unprecedented event (the Knightian uncertainty). Devereux and Yetman (2010) stress the importance of international linkages of financial institutions and propose a model of the international

\footnotetext{
${ }^{1}$ There exist several structural problems, such as societal aging, low productivity growth and low interest rates. The last point will be discussed below.
} 
transmission of shocks through de-leveraging across financial institutions. They also argue that the traditional trade linkages alone cannot explain the simultaneous and massive deterioration worldwide. Both, however, do not offer any theoretical explanation why a country like Japan experienced a much larger drop in output than the United States during the recent financial crisis. It naturally becomes an interesting research agenda to investigate alternative explanations of this particular output collapse. In the context of this paper, we propose a binding zero lower bound at the onset of the output collapse in Japan as an alternative explanation.

One distinct feature of the Japanese economy during this time is low nominal interest rates and inflation expectations. In this paper, we show that when a small open economy experiences a sufficiently large negative export demand shock, it is vulnerable to falling into a zero bound trap. In addition, such a shock can have very large impact on the economy compared to the case when the zero bound is not a binding constraint. We extend the framework of Eggertsson and Woodford (2003) and Christiano (2004) to the small open economy, to make these points.

There exist several related studies. Among them, the studies closest to ours is Bodenstein, Erceg, and Guerrieri (2009). They find that the effect of foreign demand shock is significantly amplified when the domestic economy is constrained by the zero bound on nominal interest rates. On the contrary, Backus, Kehoe, and Kydland (1992) based on the International Real Business Cycle (IRBC) model or Lubik and Schorfheide (2005) based on the New Open Economy Macroeconomics (NOEM) model, find that these are small. Although the aim of the paper by Bodenstein, Erceg, and Guerrieri (2009) is similar to ours, there are several differences. First, we use a simple model calibrated to the Japanese economy. We obtain all results analytically and therefore intuitive explanation becomes possible. Second, we show that the shock occurred in the United States during the midst of the recent financial crisis is large enough for the Japanese economy again to be constrained by the zero lower bound. Finally, albeit minor, the small open economy model is considered instead of the two country model. Concerning the second point above, Jeanne (2009) also shows that a negative demand shock in one country can push the world to the global liquidity trap, but does not focus on the multiplier of the foreign shock. ${ }^{2}$

Since the export demand shock works similarly to the government ex-

\footnotetext{
${ }^{2}$ Jeanne (2009) and Cook and Devereux (2010) examine the role and international spillover of monetary and fiscal policy in the global liquidity trap. Fujiwara, Sudo, and Teranishi (2010) and Fujiwara, Nakajima, Sudo, and Teranishi (2010) study the optimal monetary policy cooperation, while Fujiwara and Ueda (2010) investigate the fiscal multiplier and spillover, under the global liquidity trap.
} 
penditure shock, this paper is also closely related to such recent studies on the fiscal multiplier under the zero bound as Christiano (2004), Christiano, Eichenbaum, and Rebelo (2009), Eggertsson (2010), or Woodford (2010). ${ }^{3}$ When the economy is caught by the zero lower bound, traditional monetary policy implemented by means of a interest rate rule has lost any impact on the real economy. Real interest rates cannot be raised in response to the fiscal stimulus. As a result, fiscal multiplier becomes very large. The basic intuition behind our result is quite analogous to this high fiscal multiplier under the zero bound constraint.

The remainder of the paper is structured as follows. Section 2 describes the model. Section 3 reports our main results based on the framework of Eggertsson and Woodford (2003). In section 4, we check the robustness of our main findings in section 3 by using the alternative methodology proposed by Christiano (2004). Section 5 concludes.

\section{Complete Markets Model}

This section describes the model. Our main discussion uses the assumption that financial markets are complete. That is, securities are traded contingent upon every possible state of the world, including the state of the world in which the zero lower bound on the nominal rate of interest is binding. One reason we do this, is to clarify the point that the negative consequences of a binding lower bound do not depend upon financial market incompleteness. Another reason is that, as shown by Galí and Monacelli (2005), the technical analysis of a small open economy is greatly simplified by the assumption of complete markets. In particular, it is possible for us to derive all the relevant results analytically. This is not only because we adopt the assumption of complete markets, but also because we characterize the scenario in which the lower bound binds with a suitable adoption of the approach taking in Eggertsson and Woodford (2003).

Because we adopt the assumption of complete markets, it is convenient to make use of the history notation. That is, let $s_{t} \in S$ denote all the possible states of the world that can occur in period $t$. Let

$$
s^{t}=\left(s_{0}, s_{1}, \ldots, s_{t}\right)
$$

\footnotetext{
${ }^{3}$ Recent studies such as Braun and Waki (2010) and Braun and Körber (2010) have shown that the multiplier can be biased when the zero lower bound is binding and when log-linear methods are used to solve the economy. In addition, Erceg and Lindé (2010) document that the size of fiscal multiplier critically depends on its timing and how the expenditure will eventually be financed. To numerically compute the size of the export demand multiplier under these settings is left for our future research.
} 
denote the history up until period $t$ of the realized states of the world. $s^{t}$ is known at time $t$. We denote the probability of history $s^{t}$ by $\mu\left(s^{t}\right)$. The set of states, $S$, contains only two elements. One is associated with a low level of exports (so low, that the lower bound is binding in equilibrium) and the other is associated with a 'normal' level of exports. We explain this in greater detail below.

\subsection{Households}

Household preferences have the following representation:

$$
\sum_{t=0}^{\infty} \beta^{t} \sum_{s^{t}} \mu\left(s^{t}\right)\left[u\left(c\left(s^{t}\right)\right)-v\left(N\left(s^{t}\right)\right)\right], 0<\beta<1,
$$

where $c\left(s^{t}\right)$ and $N\left(s^{t}\right)$ denote consumption and employment in history $s^{t}$, respectively. The parameter, $\beta$, corresponds to the subjective discount factor. The household budget constraint is

$$
\begin{aligned}
& W\left(s^{t}\right) N\left(s^{t}\right)+\Pi\left(s^{t}\right)+\mathcal{E}\left(s^{t}\right)\left(1+R^{f}\left(s^{t-1}\right)\right) b^{f}\left(s^{t-1}\right) \\
& +\left(1+R\left(s^{t-1}\right)\right) b\left(s^{t-1}\right)+B\left(s^{t}\right) \\
\geq & \sum_{s_{t+1}} Q\left(s_{t+1}, s^{t}\right) B\left(s_{t+1}, s^{t}\right)+b\left(s^{t}\right)+\mathcal{E}\left(s^{t}\right) b^{f}\left(s^{t}\right)+P^{c}\left(s^{t}\right) C\left(s^{t}\right)
\end{aligned}
$$

where $W\left(s^{t}\right)$ and $\Pi\left(s^{t}\right)$ denote the wage rate and lump sum profits in $s^{t}$, in domestic currency units. Also, $b\left(s^{t}\right)$ denotes the quantity of domestic currency bonds purchased in $s^{t}$. These bonds pay off $b\left(s^{t}\right)\left(1+R\left(s^{t}\right)\right)$ units of domestic currency in each history, $\left(s^{t}, s_{t+1}\right)$. The object, $b^{f}\left(s^{t}\right)$, denotes the quantity of foreign currency bonds purchased in $s^{t}$ which pay off $\left(1+R^{f}\left(s^{t}\right)\right) b^{f}\left(s^{t}\right)$ units of foreign currency in each history, $\left(s^{t}, s_{t+1}\right)$. In the above expression, $\mathcal{E}\left(s^{t}\right)$ denotes the exchange rate (units of domestic currency per unit of foreign currency) in history $s^{t}$. The object, $B\left(s_{t+1}, s^{t}\right)$, is an Arrow security. It is the quantity of domestic currency to be delivered in period $t+1$ if state $s_{t+1}$ is realized, conditional on history, $s^{t}$. The associated price is $Q\left(s_{t+1}, s^{t}\right)$. Finally, $P^{c}\left(s^{t}\right)$ denotes the price of consumption goods in history $s^{t}$.

The household maximizes utility subject to its budget constraint and taking as given prices, wages, exchange rates and rates of return. 


\section{$2.2 \quad$ Firms}

A homogeneous good is produced by a representative, competitive firm using the following technology:

$$
Y\left(s^{t}\right)=\left(\int_{0}^{1} Y\left(s^{t}, i\right)^{\frac{\varepsilon-1}{\varepsilon}} d i\right)^{\frac{\varepsilon}{\varepsilon-1}}, \varepsilon>1 .
$$

Homogeneous good firms take input prices, $P\left(s^{t}, i\right)$, and output prices, $P\left(s^{t}\right)$, as given and beyond their control. The parameter, $\varepsilon$, corresponds to the elasticity of substitution among intermediate goods. Profit maximization leads to the following first order condition:

$$
Y\left(s^{t}, i\right)=\left(\frac{P\left(s^{t}\right)}{P\left(s^{t}, i\right)}\right)^{\varepsilon} Y\left(s^{t}\right) .
$$

The $i^{t h}, i \in(0,1)$, intermediate good is produced by a monopolist using the following technology:

$$
Y\left(s^{t}, i\right)=N\left(s^{t}, i\right),
$$

where $N\left(s^{t}, i\right)$ denotes employment. The real marginal cost of production for the $i^{\text {th }}$ monopolist is

$$
M C\left(s^{t}\right)=\frac{W\left(s^{t}\right)}{P\left(s^{t}\right)}
$$

The $i^{\text {th }}$ monopolist maximizes profits subject to its demand curve, (1), and Calvo price frictions. In particular, the monopolist may optimize its price, $P\left(s^{t}, i\right)$, with probability $1-\theta$ and with probability $\theta$ it sets its price as follows:

$$
P\left(s^{t}, i\right)=P\left(s^{t-1}, i\right) .
$$

The domestic consumption good is produced by a competitive, representative firm using the following production function:

$$
C\left(s^{t}\right)=\left[\left(1-\omega_{c}\right)^{\frac{1}{\eta_{c}}} C^{d}\left(s^{t}\right)^{\frac{\eta_{c}-1}{\eta_{c}}}+\omega_{c}^{\frac{1}{\eta_{c}}} C^{m}\left(s^{t}\right)^{\frac{\eta_{c}-1}{\eta_{c}}}\right]^{\frac{\eta_{c}}{\eta_{c}-1}}, \eta_{c}, \omega_{c}>0 .
$$

Here, $C^{d}\left(s^{t}\right)$ and $C^{m}\left(s^{t}\right)$ are the quantities of the domestic homogeneous good and a foreign imported good used in production. The parameter, $\eta_{c}$, corresponds to the elasticity of substitution between domestic and foreign inputs and $\omega_{c}$ corresponds to the share of foreign inputs in production. The price of the input, $C^{d}\left(s^{t}\right)$, is $P\left(s^{t}\right)$. The price of $C^{m}\left(s^{t}\right)$, in domestic currency units, is $\mathcal{E}\left(s^{t}\right) P^{f}\left(s^{t}\right)$, where $P^{f}\left(s^{t}\right)$ denotes the price of foreign goods. 
We denote exports by $X\left(s^{t}\right)$. The demand for exports is assumed to be given by

$$
X\left(s^{t}\right)=\left(\frac{P\left(s^{t}\right) / \mathcal{E}\left(s^{t}\right)}{P^{f}\left(s^{t}\right)}\right)^{-\eta_{f}} Y^{f}\left(s^{t}\right),
$$

where the numerator in the above expression is the price of exports in foreign currency units. The parameter, $\eta_{f}$, corresponds to the elasticity of substitution of exported goods. The demand for exports is a function of this price, relative to the foreign goods price.

Foreign demand, $Y^{f}\left(s^{t}\right)$, is the single exogenous stochastic process in the model. We assume

$$
Y^{f}\left(s^{t}\right) \in\left(Y^{f, l}, Y^{f, n}\right),
$$

where

$$
Y^{f, l}<Y^{f, n}
$$

Foreign demand takes on a normal value, $n$, or a low value, $l$. We assume that when foreign demand takes on a normal value, the probability of falling to its low value is $\phi$. When foreign demand takes on its low value, the probability of remaining at its normal value is $p$. We suppose that $\phi$ is positive, but extremely small, so that the normal level of export demand is essentially an absorbing state.

\subsection{Market Clearing and Monetary Policy}

Clearing in the labor market requires

$$
N\left(s^{t}\right)=\int_{0}^{1} N\left(s^{t}, i\right) d i
$$

while clearing in domestic homogeneous goods market requires

$$
Y\left(s^{t}\right)=C^{d}\left(s^{t}\right)+X\left(s^{t}\right) .
$$

Following the argument in Yun (2005), output of the homogeneous domestic good is related to aggregate employment by

$$
Y\left(s^{t}\right)=p^{*}\left(s^{t}\right) N\left(s^{t}\right),
$$

where

$$
p^{*}\left(s^{t}\right)=\frac{1}{(1-\theta)\left(\frac{1-\theta\left(1+\pi\left(s^{t}\right)\right)^{\varepsilon-1}}{1-\theta}\right)^{\frac{\varepsilon}{\varepsilon-1}}+\frac{\theta\left(1+\pi\left(s^{t}\right)\right)^{\varepsilon}}{p^{*}\left(s^{t-1}\right)}} .
$$


Monetary policy is assumed to be governed by a Taylor (1993) type rule. Let

$$
\begin{aligned}
Z\left(s^{t}\right)= & r+(1-\rho)\left[\alpha_{\pi} \sum_{s_{t+1}} \mu\left(s_{t+1} \mid s^{t}\right) \pi\left(s^{t+1}\right)+\alpha_{Y} \hat{Y}\left(s^{t}\right)\right] \\
& +\rho\left[R\left(s^{t-1}\right)-r\right],
\end{aligned}
$$

where

$$
r=\frac{1}{\beta}-1, \alpha_{\pi}>1, \alpha_{Y}>0
$$

Then,

$$
R\left(s^{t}\right)=\left\{\begin{array}{cc}
Z\left(s^{t}\right) & Z\left(s^{t}\right) \geq 0 \\
0 & Z\left(s^{t}\right)<0
\end{array}\right\} .
$$

As a benchmark analysis, we set $\rho=0$, but later you will see that whether $\rho>0$ or not is irrelevant when computing the multiplier.

\subsection{Equilibrium}

We adopt a standard sequence-of-markets equilibrium concept. We use the following functional forms:

$$
u(c)=\frac{c^{1-\frac{1}{\sigma}}}{1-\frac{1}{\sigma}}, v(N)=\psi \frac{N^{1+\gamma}}{1+\gamma}, \psi, \sigma, \gamma>0 .
$$

As appendix A shows the details of the derivation, we log-linearize the equilibrium conditions about the steady state in which exports are at their normal level and inflation is zero. The equilibrium conditions in this model can be summarized by three equations, namely the new Keynesian Phillips Curve, the dynamic IS curve and monetary policy rule, as in the standard new Keynesian model:

$$
\begin{aligned}
d \pi_{t} & =\kappa\left(\alpha_{C} \hat{C}_{t}+\gamma X_{Y} \hat{Y}_{t}^{f}\right)+\beta d \pi_{t+1} \\
\hat{C}_{t} & =-\sigma \delta\left(d R_{t}-d \pi_{t+1}\right)+\hat{C}_{t+1}, \\
d R_{t} & =\max \left[-r,(1-\rho)\left(\alpha_{\pi} d \pi_{t+1}+\alpha_{Y} \alpha_{N} \hat{C}_{t}\right)+\rho d R_{t-1}\right]
\end{aligned}
$$

where

$$
\begin{aligned}
\kappa & =\frac{(1-\theta)(1-\beta \theta)}{\theta}, \alpha_{C}=\frac{1+\Theta}{\sigma\left(1-\omega_{c} q^{1-\eta_{c}}\right)}, \alpha_{N}=\frac{\Theta}{\gamma \sigma\left(1-\omega_{c} q^{1-\eta_{c}}\right)} \\
\delta & \equiv \frac{\left(1-\omega_{c} q^{1-\eta_{c}}\right)\left[1-\omega_{c}+\omega_{c}\left(p^{c} q\right)^{1-\eta_{c}}\right]}{\left(1-\omega_{c} q^{1-\eta_{c}}\right)\left[1-\omega_{c}+\omega_{c}\left(p^{c} q\right)^{1-\eta_{c}}\right]+\omega_{c}\left(p^{c} q\right)^{1-\eta_{c}}}, \\
\Theta & =\gamma\left[\left(1-\omega_{c}\right)\left(p^{c}\right)^{\eta_{c}} C_{Y}\left(\eta_{c} \omega_{c} q^{1-\eta_{c}}+\sigma\left(1-\omega_{c} q^{1-\eta_{c}}\right)\right)+X_{Y} \eta_{f}\right] .
\end{aligned}
$$


$q$ and $p^{c}$ denote steady state values of the real exchange rate, and the relative price, $P^{c}\left(s^{t}\right) / P\left(s^{t}\right)$, respectively.

\section{Export Shocks and the Zero Bound Trap}

We consider a situation in which $\hat{Y}_{t}^{f} \in\left\{\hat{Y}^{f}, 0\right\}$, where $Y^{f}<0$. When $\hat{Y}_{t}^{f}=\hat{Y}^{f}, \hat{Y}_{t}^{f}$ returns in subsequent periods to its value of 0 with constant probability, $1-p$. When $\hat{Y}_{t}^{f}=0$, there is a constant probability, $\phi$, of transiting to a value of $\hat{Y}^{f}$. We set $\phi>0$, but so small that its impact on the computations can be ignored.

We first show that with the sizable export demand shock, a small open economy can fall into the zero bound trap. We, then, show that the export demand multiplier becomes very large when the economy is constrained by the zero bound.

\subsection{Zero Bound Trap}

We follow Eggertsson and Woodford (2003) in conjecturing that the equilibrium has the following properties: the lower bound on the nominal rate of interest is binding as long as $\hat{Y}_{t}^{f}<0$, and the equilibrium is characterized by two sets of values for the variables: steady state immediately upon the resumption of $\hat{Y}_{t}^{f}=0$ and another set of values while $\hat{Y}_{t}^{f}<0$. As in Eggertsson and Woodford (2003), using (9) and (10), we compute the allocations when $\hat{Y}_{t}^{f}=\hat{Y}^{f}$ as follows:

$$
\begin{aligned}
\hat{C}^{l} & =\frac{\sigma \delta r}{1-p}+\frac{p \sigma \delta}{1-p} \pi^{l}, \\
\pi^{l} & =\frac{\kappa \alpha_{C}}{1-\beta p} \hat{C}^{l}+\frac{\kappa \alpha_{X}}{1-\beta p} \hat{Y}^{f}
\end{aligned}
$$

where $\hat{C}^{l}$ and $\pi^{l}$ denote the deviation of consumption and inflation, respectively, from their steady state values, in the state, $\hat{Y}_{t}^{f}=\hat{Y}^{f}$. In the above expression, we impose the zero bound by setting $d R_{t}=-r$. The above system is solved as follows:

$$
\begin{gathered}
\pi^{l}=\frac{\sigma \delta \kappa \alpha_{C} r+(1-p) \kappa \gamma X_{Y} \hat{Y}^{f}}{(1-\beta p)(1-p)-\kappa \alpha_{C} \sigma \delta p}, \\
\hat{C}^{l}=\frac{\sigma \delta\left(r+p \pi^{l}\right)}{1-p} .
\end{gathered}
$$


To verify that this is in fact an equilibrium, it is necessary to confirm $Z^{l} \leq 0$. From (11), this condition is

$$
Z^{l}=r+\alpha_{\pi} p \pi^{l}+\alpha_{Y} \alpha_{N} \hat{C}_{t} \leq 0
$$

with

$$
(1-\beta p)(1-p)-\kappa \alpha_{C} \sigma \delta p>0 .
$$

The latter is the condition to avoid a deflationary black hole. As shown in Eggertsson (2010), when $(1-\beta p)(1-p)-\kappa \alpha_{c} \sigma \delta p=0$, (14) and (15) become parallel and no solution exists. Furthermore, if (17) is violated, (12) becomes positively more steeper than (13).

To test whether the conditions in (16) and (17) are satisfied, we simulate the model under the calibrated parameters shown in Table 1. Policy

Table 1: Parameter Calibration

\begin{tabular}{lll}
\hline \hline Parameters & Values & Explanation \\
\hline$\alpha_{\pi}$ & 1.5 & Policy parameter on inflation \\
$\alpha_{Y}$ & 0.5 & Policy parameter on output gap \\
$\beta$ & 0.9975 & Discount factor \\
$\psi$ & 100.56 & Weight on labor disutility \\
$\gamma$ & 2.23 & Elasticity of labor supply \\
$\varepsilon$ & 5 & Elasticity of substituion among domestic consumer goods \\
$\eta^{c}$ & 5 & Elasticity of substituion between domestic and foreign goods \\
$\eta^{f}$ & 5 & Export elasticity to the world demand \\
$\rho$ & 0 or 0.7 & Policy parameter on lag \\
$\sigma$ & 0.58 & Intertemporal Elasticity of Substitution \\
$\omega^{c}$ & 0.1 & Consumption goods import share \\
$\theta$ & 0.75 & Calvo parameter \\
$X_{Y}$ & 0.14 & Export share \\
\hline
\end{tabular}

rule parameters, $\alpha_{\pi}, \alpha_{Y}$ and $\rho$, are taken from Christiano, Ilut, Motto, and Rostagno (2010) on the simulation of the Japanese economy. $\gamma$ and $\sigma$ are estimated parameters in Fujiwara, Hirose, and Shintani (2010). Others are calibrated: $\beta$ is set so that the annualized steady state interest rate is $1 \% ; \psi$ is set so that the steady state hours worked is 0.3 (30\% of time endowment); elasticities are set at the standard values with $20 \%$ markups and equally ir- 


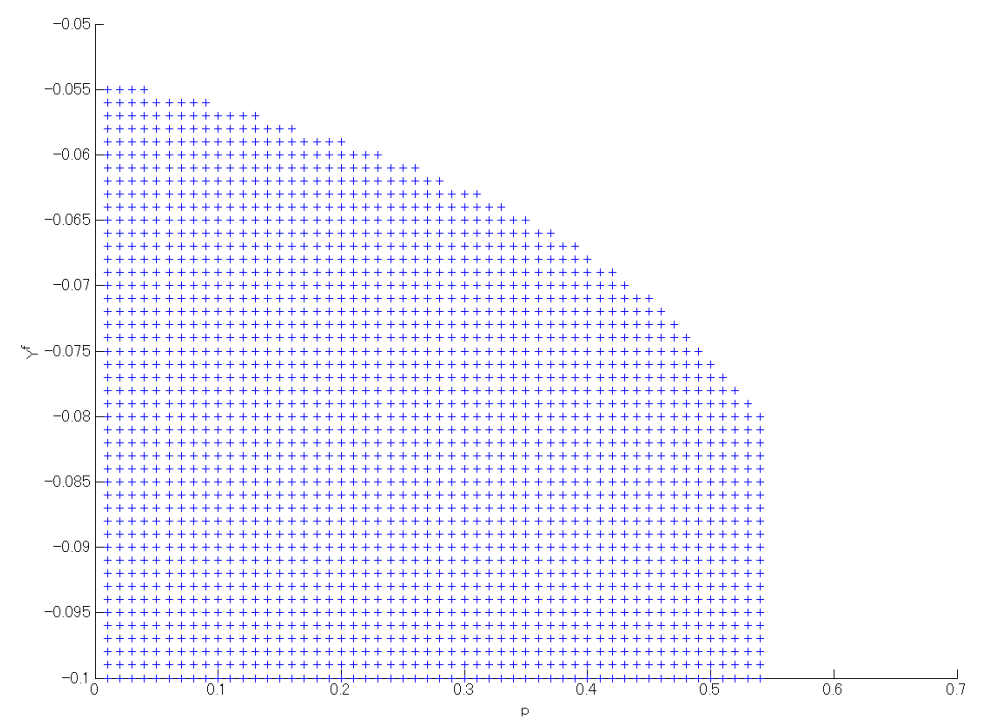

Figure 2: Zero Bound Region

respective of goods differences; ${ }^{4} \theta$ is also set at the conventional value ${ }^{5} \omega^{c}$ and $X_{Y}$ are calibrated to match the data.

The dots in Figure 2 display the area where conditions (16) and (17) are satisfied in the $p-\hat{Y}^{f}$ diagram. Note first that no plots with high $p$ means that this area does not satisfy the condition $(17),{ }^{6}$ namely

$$
p<\frac{\left(1+\beta+\kappa \alpha_{C} \sigma \delta\right)-\sqrt{\left(1+\beta+\kappa \alpha_{C} \sigma \delta\right)^{2}-4 \beta}}{2 \beta} \approx 0.55 .
$$

Also, $\hat{Y}^{f}$ must be, at least, as large as $-5.5 \%$ of the output so that (16) should hold. This implies that the export demand shock must be sizable so that a small open economy is caught by the zero bound trap. This result is in line with the previous studies on the effect of external shocks such as Backus, Kehoe, and Kydland (1992) based on the IRBC model and Lubik and Schorfheide (2005) based on the NOEM model. According to them, the

\footnotetext{
${ }^{4}$ This calibration is also employed in the Bayesian estimation of the Japanese economy by Sugo and Ueda (2008).

${ }^{5}$ Estimated models usually assume some indexation. Therefore, we calibrate this parameter instead of using the estimated value.

${ }^{6}$ Under the calibrated parameters in Table 1 , one root for $(1-\beta p)(1-p)-\kappa \alpha_{c} \sigma \delta p=0$ is larger than unity.
} 
multiplier from the foreign technology or demand shock is small. Figure 2 together with Figure 1, however, illustrates that the shock occurred in the United States during the recent financial crisis is sizable and large enough to make the Japanese economy again constrained by the zero bound trap. ${ }^{7}$

\subsection{Export Demand Multiplier}

In this section, we show that the export demand multiplier becomes very large under the zero bound constraint. Appendix A shows that the output dynamics can be expressed only with consumption and the export demand shock:

$$
\hat{Y}_{t}=\frac{\Theta}{\gamma \sigma\left(1-\omega_{c} q^{1-\eta_{c}}\right)} \hat{C}_{t}+X_{Y} \hat{Y}_{t}^{f},
$$

Thus, the export demand multiplier, which we seek for, is defined as

$$
\frac{d Y}{d Y^{f}}=\frac{1}{X_{Y}} \frac{d \hat{Y}_{t}}{d \hat{Y}_{t}^{f}}=\frac{1}{X_{Y}}\left(\frac{\partial \hat{Y}_{t}}{\partial d \hat{C}_{t}} \frac{d \hat{C}_{t}}{d \hat{Y}_{t}^{f}}+\frac{d \hat{Y}_{t}}{d \hat{Y}_{t}^{f}}\right) .
$$

\subsubsection{Without Zero Bound}

As a reference, we first compute the multiplier when the zero bound is not a binding constraint.

With (18) in hand, (9) and (10) can be re-written as

$$
\begin{aligned}
d \pi_{t} & =\frac{\gamma \kappa}{\Theta} \hat{x}_{t}+\beta d \pi_{t+1}, \\
\hat{x}_{t} & =-\frac{\delta \Theta}{\gamma\left(1-\omega_{c} q^{1-\eta_{c}}\right)}\left(d R_{t}-d \pi_{t+1}\right)+\hat{x}_{t+1}-\Theta\left(\hat{Y}_{t+1}^{f}-\hat{Y}_{t}^{f}\right),
\end{aligned}
$$

The output gap, $\hat{x}_{t}$, is defined as the deviation of the output from its flexible price level: ${ }^{8}$

$$
\hat{x}_{t}=\hat{Y}_{t}-\left(X_{Y}-\Theta\right) \hat{Y}_{t}^{f} .
$$

(20) and (21) imply that if monetary policy is conducted so that the real interest rate, $d R_{t}-d \pi_{t+1}$, is set to cancel the natural rate of interest, $\hat{r}_{t}^{n}$, namely,

$$
d R_{t}-d \pi_{t+1}=-\frac{\gamma\left(1-\omega_{c} q^{1-\eta_{c}}\right) \Theta}{\delta \Theta}\left(\hat{Y}_{t+1}^{f}-\hat{Y}_{t}^{f}\right)=-\hat{r}_{t}^{n}
$$

${ }^{7}$ The frontier is downward sloping. With higher $p$, the zero bound period, namely, recession, becomes longer. Yet, at the same time, this also implies longer periods for zero interest rate policy. The shape of the frontier is determined by the balance between these two forces. With different policy parameters, the frontier can be upward sloping.

${ }^{8}$ In an equilibrium where inflation is completely stabilized, or $d \pi_{t}=\beta d \pi_{t+1}, \hat{Y}_{t}=$ $\left(X_{Y}-\Theta\right) \hat{Y}_{t}^{f}$. This is the output under flexible price equilibrium. 
complete and simultaneous stabilization of inflation and the output gap is possible. As shown by Galí and Monacelli (2005), the welfare can be approximated by the quadratic loss function consisting of (domestic producer price) inflation and the output gap. Therefore, in this economy only with the export demand shock, complete stabilization of inflation is optimal monetary policy. Under complete price stability, we can obtain the multiplier analytically. Analytical results under complete price stability are instructive to understand the mechanism at work and ease comparisons to former studies on the effects of foreign variables and on the fiscal multiplier in the RBC models. After the intuition behind the basic result is explained, we will later show the multiplier under the Taylor type rule in (11) via impulse responses.

Under complete price stability, namely

$$
\pi_{t}=0, \forall t
$$

(10) implies

$$
\frac{d \hat{C}_{t}}{d \hat{Y}_{t}^{f}}=-\frac{\gamma X_{Y}}{\alpha_{C}}=-\frac{\gamma X_{Y} \sigma\left(1-\omega_{c} q^{1-\eta_{c}}\right)}{1+\Theta}
$$

Therefore, from (19), we can infer the export demand multiplier:

$$
\begin{aligned}
\frac{d Y}{d Y^{f}} & =\frac{1}{X_{Y}}\left(\frac{\Theta}{\gamma \sigma\left(1-\omega_{c} q^{1-\eta_{c}}\right)} \frac{d \hat{C}_{t}}{d \hat{Y}_{t}^{f}}+X_{Y}\right) \\
& =1-\frac{\Theta}{1+\Theta}=\frac{1}{1+\Theta} .
\end{aligned}
$$

Since $\Theta>0$, the multiplier does not exceed 1. Especially, under the calibrated parameters in Table 1, this turns out to be small:

$$
\frac{d Y}{d Y^{f}} \approx 0.22
$$

This small multiplier is consistent with the former findings on the small effects of foreign shock as examined in Backus, Kehoe, and Kydland (1992) and Lubik and Schorfheide (2005). At the same time, it is also related to the small but positive fiscal multiplier with the RBC models as examined in Hall (1980), Barro (1981), and Aiyagari, Christiano, and Eichenbaum (1992). Note that complete price stability implies the flexible price model. ${ }^{9}$ The positive fiscal multiplier emerges as a result of reduced consumption or increased

\footnotetext{
${ }^{9}$ There exists conceptual difference between the sticky price model with $d \pi_{t}=0, \forall t$ and the flexible price model. In the former, the price level is constant, while it is indeterminate in the latter.
} 

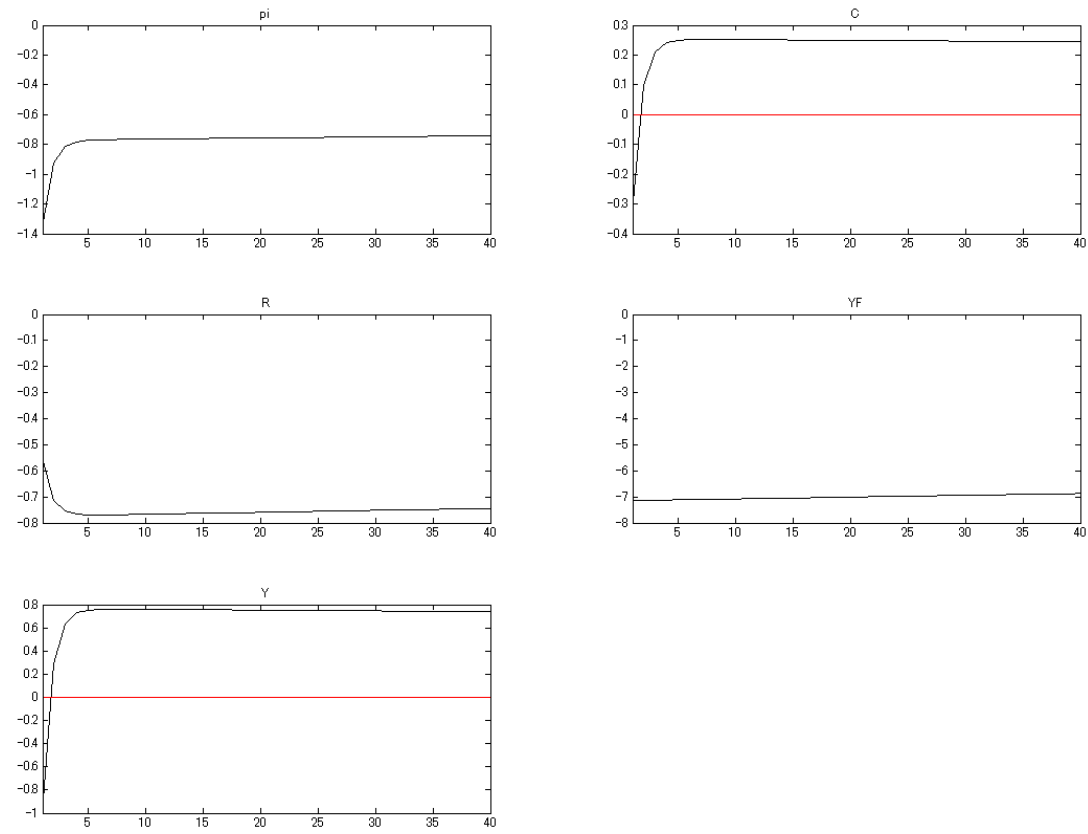

Figure 3: Impulse Responses

marginal utility out of consumption to satisfy the resource constraint. This leads to an increase in labor efforts through the first order condition of labor supply and therefore output. They, however, also show that the multiplier is small and does not exceed unity in the standard RBC model. According to the resource constraint in (5), an export demand shock triggers a similar mechanism as an government expenditure shock. Therefore, the size and sign of the export demand multiplier under flexible prices in (22) can be compared with the government spending multiplier obtained in Hall (1980), Barro (1981), and Aiyagari, Christiano, and Eichenbaum (1992).

Figure 3 below displays the impulse responses under the Taylor-type rule in (11) with $\rho=0.5$ and without the zero bound constraint. The export demand shock, whose size is $-1 \%$ of the output, is given with $\mathrm{AR}(1)$ parameter being 0.99. Although the initial impact is larger than the case with complete price stability, the decrease in the output is less than unity even with such a large negative and persistent shock. Moreover, since the negative export demand shock acts like the negative cost push shock, large deflation occurs. In reaction to this, nominal interest rates are lowered for a long period of time. 
This can be compared with the crowding out effects from fiscal expenditure. A large negative (positive) shock is somehow mitigated by lowered (raised) interest rates. Consequently, output increases, which is also enhanced by an increase in labor supply due also to the large negative wealth effects from the prolonged export demand shock. This exercise with realistic monetary policy reaction function also demonstrates that the export demand multiplier is small without the zero bound.

\subsubsection{Under Zero Bound}

Under the zero bound constraint, the story can be quiet different. To understand the intuition behind this, we first examine the benchmark case when $\rho=0$. Since there is no endogenous state variable, the equilibrium allocations are derived by solving (12) and (13). Then, with (18), we can show

$$
\frac{d \hat{C}^{l}}{d \hat{Y}^{f}}=\frac{\sigma\left(1-\omega_{c} q^{1-\eta_{c}}\right) p \delta \kappa \gamma X_{Y}}{(1-p)(1-\beta p)\left(1-\omega_{c} q^{1-\eta_{c}}\right)-p \delta \kappa(1+\Theta)} .
$$

Therefore, following (19), we can infer the export demand multiplier:

$$
\begin{aligned}
\frac{d Y^{l}}{d Y^{f}} & =\frac{1}{X_{Y}}\left[\frac{\Theta}{\gamma \sigma\left(1-\omega_{c} q^{1-\eta_{c}}\right)} \frac{d \hat{C}^{l}}{d \hat{Y}^{f}}+X_{Y}\right] \\
& =1+\frac{\Theta}{\frac{(1-p)(1-\beta p)\left(1-\omega_{c} q^{\left.1-\eta_{c}\right)}\right.}{p \delta \kappa}-(1+\Theta)} .
\end{aligned}
$$

When $\rho>0$, the calculations must be done differently, because a state variable impacts on economic dynamics when the economy transits out of the zero bound. Yet, you will see that the multiplier in (23) also represents the multiplier when $\rho>0$. Conveniently, the state variable, namely, the lagged interest rate, takes on the same value, regardless of how long the system has been in the zero bound. We solve for the equilibrium backwards, first considering economic dynamics beginning in the period when the economy emerges from the zero bound, and then considering the situation in the zero bound.

Let $\mathbf{z}^{*}=\left(\hat{C}^{*}, \pi^{*}, R^{*}-r\right)^{\prime}$ denote the $3 \times 1$ vector of values taken on by the endogenous variables in the period that the system emerges from the zero bound. With $\mathbf{z}^{*}$ at hand, from (9), (10) and (11), we can compute the values taken on by the variables in the lower bound by solving

$$
\begin{aligned}
\hat{C}^{l} & =\sigma \delta\left[\beta r+p \pi^{l}+(1-p) \pi^{*}\right]+p \hat{C}^{l}+(1-p) \hat{C}^{*} \\
\pi^{l} & =\kappa\left(\alpha_{c} \hat{C}^{l}+\alpha_{X} \hat{Y}^{f}\right)+\beta\left[p \pi^{l}+(1-p) \pi^{*}\right] .
\end{aligned}
$$




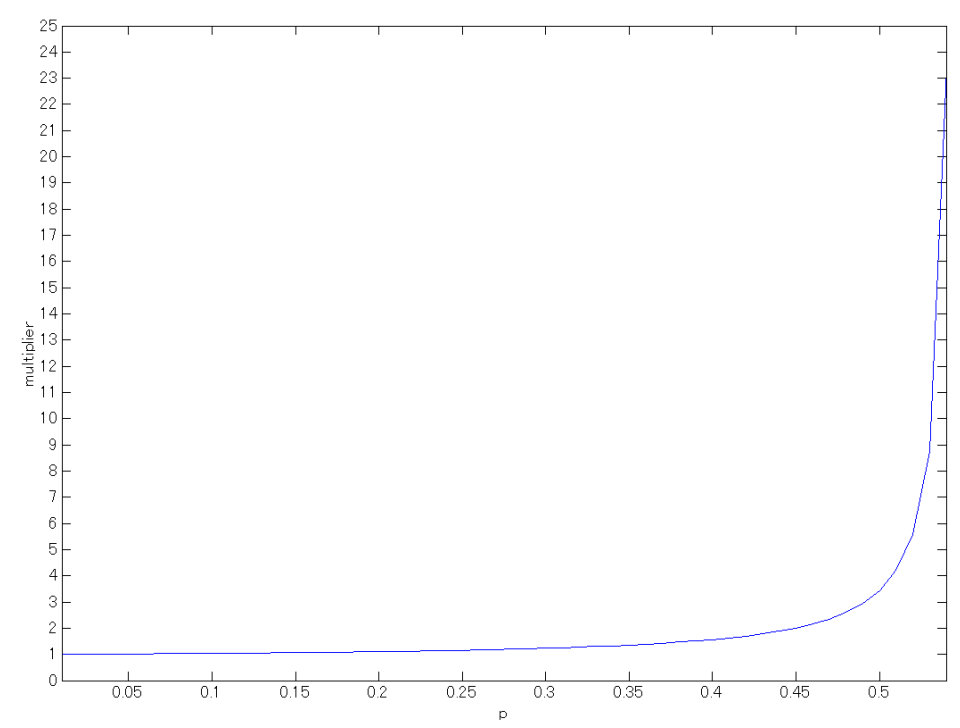

Figure 4: Multiplier under the Zero Bound

Since only endogenous state variables are the nominal interest rate, Appendix B shows that

$$
\mathbf{z}^{*}=-\mathbf{a} r .
$$

Namely, $\mathbf{z}^{*}$ are independent of the endogenous variables under the zero bound. This leads to our equivalence results, namely that the multiplier for $\rho=0$ is equal to the multiplier when $\rho>0$. To obtain $d \hat{C}^{l} / d \hat{Y}^{f}$, differentiate (24) and (25), taking into account that the variables with $*$ are not a function of $\hat{Y}^{f}$ :

$$
\begin{aligned}
\frac{d \hat{C}^{l}}{d \hat{Y}^{f}} & =\frac{\sigma \delta p}{1-p} \frac{d \pi^{l}}{d \hat{Y}^{f}} \\
\frac{d \pi^{l}}{d \hat{Y}^{f}} & =\frac{\kappa \alpha_{C}}{1-\beta p} \frac{d \hat{C}^{l}}{d \hat{Y}^{f}}+\frac{\kappa \alpha_{X}}{1-\beta p}
\end{aligned}
$$

As a result, the multiplier when $\rho>0$ is also expressed by (23).

Figure 4 shows the multiplier under the zero bound with changing $p$ until the level to a deflationary black hole. Even when $p$ is very small, the multiplier is larger than unity. As $p$ becomes larger, the multiplier increases rapidly. Especially, when $p$ is close to the critical value where the economy is caught by a deflationary black hole, the size of multiplier becomes as large as 20 . 
The result is consistent with the previous studies in the context of the external shock given by Bodenstein, Erceg, and Guerrieri (2009) or the fiscal multiplier under the zero bound constraint discussed by Christiano (2004), Christiano, Eichenbaum, and Rebelo (2009), Eggertsson (2010) and Woodford (2010). Under the zero bound constraint, since traditional monetary policy via interest rate channel is inactive, there is no endogenous stabilization mechanism, which, for example, induces a decrease in real interest rates. As a result, size of multiplier against the negative export demand shock becomes large. Christiano (2004), Christiano, Eichenbaum, and Rebelo (2009), Eggertsson (2010) and Woodford (2010) theoretically show that fiscal policy can be effective in such a situation. The detailed discussions as to why the multiplier is large in the presence of the zero bound are given below.

\subsubsection{Discussion}

The important equilibrium condition in determining the size of the multiplier is the households' optimality condition on labor supply: ${ }^{10}$

$$
M C\left(s^{t}\right) \frac{P^{c}\left(s^{t}\right)}{P\left(s^{t}\right)}=\frac{v^{\prime}\left(N\left(s^{t}\right)\right)}{u^{\prime}\left(C\left(s^{t}\right)\right)} .
$$

together with

$$
\begin{aligned}
\frac{P^{c}\left(s^{t}\right)}{P\left(s^{t}\right)} & =\left(\frac{1-\omega_{c}}{1-\omega_{c} q\left(s^{t}\right)^{1-\eta_{c}}}\right)^{\frac{1}{1-\eta_{c}}} \\
q\left(s^{t}\right) & =\frac{\xi}{u^{\prime}\left(C\left(s^{t}\right)\right)}
\end{aligned}
$$

(27) is derived from the cost minimization problem on (3). $q\left(s^{t}\right)$ in $(28)$ is the real exchange rate, derived as a result of complete risk sharing, where $\xi$ is some constant.

Under the flexible price equilibrium, $M C\left(s^{t}\right)$ is kept constant. The negative export demand shock reduces output through both domestic and international channels. The former given $P^{c}\left(s^{t}\right) / P\left(s^{t}\right)$ in (26) works as follows: consumption increases via (5); marginal utility out of consumption decreases; to reduce the marginal disutility from labor, labor supply and therefore output decrease. The latter given the denominator in the right hand side variable in (26) works as follows: decrease in the marginal utility out of consumption leads to depreciation of the real exchange rate (increase

\footnotetext{
${ }^{10}$ For the derivation of the below optimality conditions, see Appendix A.
} 
in $\left.q\left(s^{t}\right)\right)$; since $\eta_{C}$ is set larger than unity, this improves the terms on trade and lowers $P^{c}\left(s^{t}\right) / P\left(s^{t}\right) .{ }^{11}$ This also promotes a decrease in output.

When price is sticky, as shown in Figure 3, monetary policy rule also becomes a crucial factor in determining the size of the multiplier. As analytically demonstrated by Woodford (2010), if monetary policy keeps constant real interest rates, then multiplier is unity. According to the standard Euler equation, the consumption should be kept constant. Therefore, labor supply must be increased to keep the same level of consumption. On the other hand, if real interest rates are lowered in reaction to deflation and negative economic activities, the multiplier significantly decreases.

When the economy is caught by the zero bound trap. Nominal interest rates are fixed at zero. Therefore, a deflationary pressure stemming from a negative export demand shock cannot be mitigated by lowered real interest rates. Following the above arguments made by Woodford (2010), this significantly raises the multiplier. This mechanism can be also understood via (26). When monetary policy via traditional interest rate channel is inactive under the zero bound, the marginal cost falls in response to a negative export demand shock. Hence, $M C\left(s^{t}\right)$ substantially decreases. Consequently, the multiplier to the export demand shock can be large.

\section{Robustness Check}

In this section, we test the robustness of above findings. We compute the dynamic multiplier from the export demand shock. Contrary to the experiments above based on Eggertsson and Woodford (2003), we here follow Christiano (2004) and do not specify any specific stochastic process. Instead, we assume that the expected period for the zero bound trap is very long so that agent believe $d R_{t}=-r$, but the period for the negative export demand shock is very short. Considering the fact that nominal interest rates have been low for a long time, this assumption reflect some aspects of the recent Japanese economic developments.

The equilibrium conditions in (9) and (10) are re-written as

$$
\begin{aligned}
d \pi_{t} & =\Gamma \hat{Y}_{t}+\Delta \hat{Y}_{t}^{f}+\beta d \pi_{t+1}, \\
\hat{Y}_{t} & =\Phi\left(r+d \pi_{t+1}\right)+\hat{Y}_{t+1}+X_{Y}\left(\hat{Y}_{t}^{f}-\hat{Y}_{t+1}^{f}\right),
\end{aligned}
$$

\footnotetext{
${ }^{11}$ Thus, the trade elasticity is very important factor on the effects of multipliers through terms of trade. For details, see Bodenstein, Erceg, and Guerrieri (2009) and Fujiwara and Ueda (2010) in the context of the liquidity trap.
} 
where

$$
\Phi=\frac{\Theta \delta}{\gamma\left(1-\omega_{c} q^{\left.1-\eta_{c}\right)}\right.}, \Gamma=\frac{\kappa \alpha_{C} \sigma \delta}{\Phi}, \Upsilon=X_{Y} \gamma(\kappa-\Gamma) .
$$

We substitute out $\hat{C}_{t}$ by using (18). Following Christiano (2004), we solve this by recursive substitution for (29) and (30) to substitute out $d \pi_{t}$. With lag operator, (29) and (30) can be transformed into

$$
\hat{Y}_{t}=h(L) \hat{Y}_{t}^{f}+\frac{(1-\beta)\left(1-\beta L^{-1}\right) \Phi L^{-1}}{\left(1-L^{-1}\right)\left(1-\beta L^{-1}\right)-\Phi L^{-1} \Gamma},
$$

where

$$
\begin{aligned}
h(L) & =\frac{\Phi \Upsilon L^{-1}+\left(1-L^{-1}\right)\left(1-\beta L^{-1}\right) X_{Y}}{\left(1-L^{-1}\right)\left(1-\beta L^{-1}\right)-\Phi \Gamma L^{-1}} \\
& =\frac{1}{X_{Y}} \frac{\left(1-\zeta_{1} L^{-1}\right)\left(1-\zeta_{2} L^{-1}\right)}{\left(1-\lambda_{1} L^{-1}\right)\left(1-\lambda_{2} L^{-1}\right)}
\end{aligned}
$$

and

$$
\begin{aligned}
\zeta_{1}+\zeta_{2} & =1+\beta-\frac{\Phi \Upsilon}{X_{Y}}, \zeta_{1} \zeta_{2}=\beta, \\
\lambda_{1}+\lambda_{2} & =1+\beta+\Phi \Gamma, \lambda_{1} \lambda_{2}=\beta, \\
\lambda_{1} & <\zeta_{1}<\beta, \lambda_{2}>\zeta_{2}>1 .
\end{aligned}
$$

As details are shown in Appendix $\mathrm{C}$, if $\hat{Y}_{t}^{f}=1$ for $t=1, \ldots, T-1$, the export demand multiplier, $d Y^{l} / d Y^{f}$, can be expressed as follows

$$
\frac{d Y^{l}}{d Y^{f}}=1+\Phi\left(\Gamma+\frac{\Upsilon}{X_{Y}}\right)+\frac{\Phi\left(\Gamma+\frac{\Upsilon}{X_{Y}}\right)}{\lambda_{2}-\lambda_{1}}\left(\lambda_{2}^{2} \frac{1-\lambda_{2}^{T-3}}{1-\lambda_{2}}-\lambda_{1}^{2} \frac{1-\lambda_{1}^{T-3}}{1-\lambda_{1}}\right)
$$

Table 2 below displays the results from (31). We set $T-1=\{1,2,3\}$, reflecting the realistic periods of large negative export demand shock observed in Figure 1. The multiplier from the export demand shock is unity even with

Table 2: Multiplier under Alternative Computation

\begin{tabular}{llll}
\hline \hline Periods for negative $\hat{Y}^{f}$ & 1 & 2 & 3 \\
\hline$d Y^{l} / d Y^{f}$ & 1.0 & 1.3 & 10.7 \\
\hline
\end{tabular}

one time shock. Moreover, it becomes large (10.7) even when the shock lasts only for three quarters. The results from this alternative computation also assures the previous conclusion that the external shock can have very large impacts on the domestic economy when the zero bound is a binding constraint. 


\section{Conclusion}

When a small open economy experiences a sufficiently large negative export demand shock, it is vulnerable to falling into a zero bound trap. Using a simple model calibrated for the Japanese economy, we show that the shock occurred in the United States during the midst of the recent financial crisis is large enough to make the Japanese economy again constrained by the zero lower bound. In addition, we also show that such a shock can have very large impact on the economy compared to the case when the zero bound is not a binding constraint. We infer that this could be one possible explanation as to why a country like Japan experienced much larger drop in output than the United States during the recent financial crisis. 


\section{References}

Aiyagari, S. Rao, Lawrence J. Christiano, and Martin Eichenbaum (1992). "The Output, Employment, and Interest Rate Effects of Government Consumption." Journal of Monetary Economics, 30(1), 73-86.

Backus, David, K., Patrick J. Kehoe, and Finn E Kydland (1992). "International Real Business Cycles." Journal of Political Economy, 100(4), 74575 .

Barro, Robert J. (1981). "Output Effects of Government Purchases." Journal of Political Economy, 89(6), 1086-1121.

Bodenstein, Martin, Christopher J. Erceg, and Luca Guerrieri (2009). "The Effects of Foreign Shocks when Interest Rates are at Zero." Discussion paper.

Braun, Richard A., and Lena Körber (2010). "New Keynesian Dynamics in a Low Interest Rate Environment." Discussion paper.

Braun, Richard A., and Yuichiro Waki (2010). "On the Size of the Fiscal Multiplier when the Nominal Interest Rate is Zero." Discussion paper.

Caballero, Ricardo, and Pablo Kurlat (2009). "The "Surprising" Origin and Nature of Financial Crises: A Macroeconomic Policy Proposal." In Jackson Hale Symposium on "Financial Stability and Macroeconomic Policy". Federal Reserve Bank of Kansas City.

Christiano, Lawrence J. (2002). "Solving Dynamic Equilibrium Models by a Method of Undetermined Coefficients." Computational Economics, 20(12), 21-55.

Christiano, Lawrence J. (2004). "The Zero-Bound, Zero-Inflation Targetting, and Output Collapse." Mimeo, Northwestern University.

Christiano, Lawrence J., Martin Eichenbaum, and Sergio Rebelo (2009). "When is the Government Spending Multiplier Large?." NBER Working Paper 15394, National Bureau of Economic Research.

Christiano, Lawrence J., Cosmin Ilut, Roberto Motto, and Massimo Rostagno (2010). "Monetary Policy and Stock Market Booms." In Jackson Hale Symposium on "Macroeconomic Challenges: The Decade Ahead". Federal Reserve Bank of Kansas City. 
Cook, David, and Michael B. Devereux (2010). "International Monetary and Fiscal Policy Coordination in a Liquidity Trap." Discussion paper, University of British Columbia.

Devereux, Michael B., and James Yetman (2010). "Leverage Constraints and the International Transmission of Shocks." NBER Working Papers 16226, National Bureau of Economic Research, Inc.

Eggertsson, Gauti B. (2010). "What Fiscal Policy is Effective at Zero Interest Rates?." In NBER Macroconomics Annual 2010, Volume 25, NBER Chapters. National Bureau of Economic Research, Inc.

Eggertsson, Gauti B., and Michael Woodford (2003). "The Zero Bound on Interest Rates and Optimal Monetary Policy." Brookings Papers on Economic Activity, 34(2003-1), 139-235.

Erceg, Christopher J., and Jesper Lindé (2010). "Is There a Fiscal Free Lunch in a Liquidity Trap?." CEPR Discussion Papers 7624, C.E.P.R. Discussion Papers.

Fujiwara, Ippei, Yasuo Hirose, and Mototsugu Shintani (2010). "Can News Be a Major Source of Aggregate Fluctuations? A Bayesian DSGE Approach." Journal of Money, Credit and Banking (forthcoming).

Fujiwara, Ippei, Tomoyuki Nakajima, Nao Sudo, and Yuki Teranishi (2010). "Global Liquidity Trap." IMES Discussion Paper Series 10-E-11, Institute for Monetary and Economic Studies, Bank of Japan.

Fujiwara, Ippei, Nao Sudo, and Yuki Teranishi (2010). "The Zero Lower Bound and Monetary Policy in a Global Economy: A Simple Analytical Investigation." International Journal of Central Banking, 6(1), 103-134.

Fujiwara, Ippei, and Kozo Ueda (2010). "Fiscal Multiplier and Spillover under Global Liquidity Trap." IMES Discussion Paper Series 10-E-3, Institute for Monetary and Economic Studies, Bank of Japan.

Galí, Jordi, and Tommaso Monacelli (2005). "Monetary Policy and Exchange Rate Volatility in a Small Open Economy." Review of Economic Studies, $72(3), 707-734$.

Hall, Robert E. (1980). "Labor Supply and Aggregate Fluctuations." Carnegie-Rochester Conference Series on Public Policy, 12, 7-33.

Hamilton, James D. (1994). Time Series Analysis. Princeton: Princeton University Press. 
Jeanne, Olivier (2009). "The Global Liqudity Trap.” Discussion paper, Johns Hopkins University.

Lubik, Thomas A., and Frank Schorfheide (2005). "A Bayesian Look at New Open Economy Macroeconomics." In NBER Macroeconomics Annual 2005, edited by Mark Gertler, and Kenneth Rogoff, vol. 20. Cambridge: MIT Press.

Sargent, Thomas J. (1987). Macroeconomic Theory. San Diego: Academic Press, 2 edn.

Sugo, Tomohiro, and Kozo Ueda (2008). "Estimating a dynamic stochastic general equilibrium model for Japan." Journal of the Japanese and International Economies, 22(4), 476-502.

Taylor, John B. (1993). "Discretion versus Policy Rules in Practice." Carnegie-Rochester Conference Series on Public Policy, 39, 195-214.

Woodford, Michael (2010). "Simple Analytics of the Government Expenditure Multiplier." NBER Working Paper 15714, National Bureau of Economic Research.

Yun, Tack (2005). "Optimal Monetary Policy with Relative Price Distortions." American Economic Review, 95(1), 89-109. 


\section{A Derivation of the Model}

The first subsection below describes the equilibrium conditions. The following subsection shows steady states. The last subsection displays the linear expansion of the equilibrium conditions about steady state.

\section{A.1 Equilibrium Conditions}

The household first order conditions with respect to $N\left(s^{t}\right), B\left(s_{t+1}, s^{t}\right), b\left(s^{t}\right)$, $b^{f}\left(s^{t}\right)$, respectively, are

$$
\begin{aligned}
& \frac{v^{\prime}\left(N\left(s^{t}\right)\right)}{u^{\prime}\left(C\left(s^{t}\right)\right)}=\frac{W\left(s^{t}\right)}{P^{c}\left(s^{t}\right)}, \\
& \beta \mu\left(s_{t+1} \mid s^{t}\right) \frac{u^{\prime}\left(C\left(s^{t+1}\right)\right)}{u^{\prime}\left(C\left(s^{t}\right)\right)\left(1+\pi^{c}\left(s^{t+1}\right)\right)}=Q\left(s_{t+1} \mid s^{t}\right), \\
& \beta \sum_{s_{t+1}} \mu\left(s_{t+1} \mid s^{t}\right) \frac{u^{\prime}\left(C\left(s^{t+1}\right)\right)\left(1+R\left(s^{t}\right)\right)}{u^{\prime}\left(C\left(s^{t}\right)\right)\left(1+\pi^{c}\left(s^{t+1}\right)\right)}=1, \\
& \beta \sum_{s_{t+1}} \mu\left(s_{t+1} \mid s^{t}\right) \frac{e\left(s^{t+1}\right) u^{\prime}\left(C\left(s^{t+1}\right)\right)\left(1+R^{f}\left(s^{t}\right)\right)}{u^{\prime}\left(C\left(s^{t}\right)\right)\left(1+\pi^{c}\left(s^{t+1}\right)\right)}=1 \text {, }
\end{aligned}
$$

where

$$
e\left(s^{t+1}\right) \equiv \frac{\mathcal{E}\left(s^{t+1}\right)}{\mathcal{E}\left(s^{t}\right)}, 1+\pi^{c}\left(s^{t+1}\right)=\frac{P^{c}\left(s^{t+1}\right)}{P^{c}\left(s^{t}\right)}, \mu\left(s_{t+1} \mid s^{t}\right)=\frac{\mu\left(s^{t+1}\right)}{\mu\left(s^{t}\right)} .
$$

We assume that foreigners also participate in the markets for $B\left(s^{t}\right)$. Let $P^{f, c}\left(s^{t}\right)$ denote the price of the foreign consumption good. Optimality in the choice of $B\left(s_{t+1}, s^{t}\right)$ by foreigners leads to the following condition:

$$
Q\left(s_{t+1}, s^{t}\right)=\beta \mu\left(s_{t+1} \mid s^{t}\right) \frac{u^{\prime}\left(C^{f}\left(s^{t+1}\right)\right)}{u^{\prime}\left(C^{f}\left(s^{t}\right)\right)\left(1+\pi^{f}\left(s^{t+1}\right)\right) e\left(s^{t+1}\right)},
$$

for each $s_{t+1}, s^{t}$. Here, $C^{f}\left(s^{t}\right)$ denotes foreign consumption, $\pi^{f}\left(s^{t}\right)$ denotes the inflation rate in $P^{f, c}\left(s^{t}\right)$. Implicitly, we assume the foreign agents have the same utility function, discount rate, and beliefs about the probabilities of the different states of the world. Combining (33) and (36), we obtain

$$
\frac{u^{\prime}\left(C^{f}\left(s^{t+1}\right)\right) q\left(s^{t}\right)}{u^{\prime}\left(C^{f}\left(s^{t}\right)\right) q\left(s^{t+1}\right)}=\frac{u^{\prime}\left(C\left(s^{t+1}\right)\right)}{u^{\prime}\left(C\left(s^{t}\right)\right)}
$$

where the real exchange rate, $q\left(s^{t}\right)$, is defined as follows:

$$
q\left(s^{t}\right)=\frac{\mathcal{E}\left(s^{t}\right) P^{f, c}\left(s^{t}\right)}{P^{c}\left(s^{t}\right)} .
$$


In the spirit of our small country analysis, we assume that foreign consumption is constant, independent of $s^{t}$, so that the complete markets condition can be expressed as follows:

$$
q\left(s^{t+1}\right) u^{\prime}\left(C\left(s^{t+1}\right)\right)=q\left(s^{t}\right) u^{\prime}\left(C\left(s^{t}\right)\right),
$$

for all $s^{t}, s_{t+1}$. We express this condition as

$$
q\left(s^{t}\right) u^{\prime}\left(C\left(s^{t}\right)\right)=\xi,
$$

for all $s^{t}$.

We now turn to optimization by intermediate good firms. The $1-\theta$ intermediate good firms that can set prices optimally do so as follows:

$$
\tilde{p}\left(s^{t}\right)=\frac{K\left(s^{t}\right)}{F\left(s^{t}\right)},
$$

where $\tilde{p}\left(s^{t}\right)$ is the price set by an optimizing intermediate good firm, divided by $P\left(s^{t}\right)$. The numerator and denominator of the previous terms satisfy the following relationships:

$$
\begin{aligned}
K\left(s^{t}\right)= & \frac{\varepsilon}{\varepsilon-1} u^{\prime}\left(C\left(s^{t}\right)\right) Y\left(s^{t}\right) M C\left(s^{t}\right) \\
& +\theta \beta \sum_{s_{t+1}} \mu\left(s_{t+1} \mid s^{t}\right)\left(\frac{1}{1+\pi\left(s^{t+1}\right)}\right)^{-\varepsilon} K\left(s^{t+1}\right), \\
F\left(s^{t}\right)= & u^{\prime}\left(C\left(s^{t}\right)\right) Y\left(s^{t}\right) \\
& +\theta \beta \sum_{s_{t+1}} \mu\left(s_{t+1} \mid s^{t}\right)\left(\frac{1}{1+\pi\left(s^{t+1}\right)}\right)^{1-\varepsilon} F\left(s^{t+1}\right), \\
\frac{K\left(s^{t}\right)}{F\left(s^{t}\right)=} & {\left[\frac{1-\theta\left(1+\pi\left(s^{t}\right)\right)^{\varepsilon-1}}{1-\theta}\right]^{\frac{1}{1-\varepsilon}} . }
\end{aligned}
$$

Combining (2) with (32), we obtain

$$
M C\left(s^{t}\right)=\frac{v^{\prime}\left(N\left(s^{t}\right)\right)}{u^{\prime}\left(C\left(s^{t}\right)\right)} p^{c}\left(s^{t}\right)
$$

where

$$
p^{c}\left(s^{t}\right) \equiv \frac{P^{c}\left(s^{t}\right)}{P\left(s^{t}\right)} .
$$

Profit maximization by the producer of domestic consumption goods implies: 


$$
\begin{aligned}
C^{d}\left(s^{t}\right) & =\left(1-\omega_{c}\right)\left(p^{c}\left(s^{t}\right)\right)^{\eta_{c}} C\left(s^{t}\right) \\
C^{m}\left(s^{t}\right) & =\omega_{c}\left(q\left(s^{t}\right)\right)^{-\eta_{c}} C\left(s^{t}\right) .
\end{aligned}
$$

According to (43) the demand for the domestically produced input, $C^{d}$, is a decreasing function of the input price, $P$, relative to the output price, $P^{c}$. According to (44), the demand for the imported good, $C^{m}$, is also a decreasing of the input price, $\mathcal{E} P^{f, c}$, relative to the output price. Substituting (43) and (44) into the production function, (3), we obtain

$$
p^{c}\left(s^{t}\right)=\left[\left(1-\omega_{c}\right)+\omega_{c}\left(p^{c}\left(s^{t}\right) q\left(s^{t}\right)\right)^{1-\eta_{c}}\right]^{\frac{1}{1-\eta_{c}}} .
$$

The demand for exports, (4), in terms of scaled prices, is

$$
X\left(s^{t}\right)=\left(q\left(s^{t}\right) p^{c}\left(s^{t}\right)\right)^{\eta_{f}} Y^{f}\left(s^{t}\right) .
$$

Equation (42) and (45) imply

$$
1+\pi^{c}\left(s^{t}\right) \equiv\left(1+\pi\left(s^{t}\right)\right)\left[\frac{\left(1-\omega_{c}\right)+\omega_{c}\left(p^{c}\left(s^{t}\right) q\left(s^{t}\right)\right)^{1-\eta_{c}}}{\left(1-\omega_{c}\right)+\omega_{c}\left(p^{c}\left(s^{t-1}\right) q\left(s^{t-1}\right)\right)^{1-\eta_{c}}}\right]^{\frac{1}{1-\eta_{c}}} .
$$

Equality of supply and demand for the homogeneous domestic good implies, after substituting (43) into (5):

$$
Y\left(s^{t}\right)=\left(1-\omega_{c}\right)\left(p^{c}\left(s^{t}\right)\right)^{\eta_{c}} C\left(s^{t}\right)+X\left(s^{t}\right) .
$$

The 14 variables whose values are determined in equilibrium are

$$
C, F, K, N, X, M C, Y, R, e, p^{*}, p^{c}, q, \pi, \pi^{c},
$$

for each possible $s^{t}$. The 14 equilibrium conditions are: (6), (7), (34), (35), (37), (38), (39), (40), (41), (45), (46), (47), (48), plus monetary policy, (8).

\section{A.2 Steady State}

From (7), (8), (34), (35), (38), (39), (40), and (47), we can easily obtain

$$
e=1, p^{*}=1, \pi^{c}=\pi=0, R=R^{f}=1 / \beta-1, M C=\frac{\varepsilon-1}{\varepsilon} .
$$

In the equilibrium conditions that we use to solve these variables, there are two parameters, $Y^{f}$ and $\xi$, that we do not know how to calibrate. Instead, 
we fix the consumption and export to output ratios, $q$ and $X_{Y}$, respectively. Especially, we seek for the steady states when

$$
p^{c}=1
$$

Then, from (45),

$$
q=1
$$

With these assumptions, by combining (6), (37), (41), (45), (46), and (48), the steady states for other variables are computed as follows:

$$
\begin{aligned}
& C=\left[\frac{\left(1-X_{Y}\right)\left(\frac{\varepsilon-1}{\varepsilon \psi}\right)^{\frac{1}{\gamma}}}{1-\omega_{c}}\right]^{\frac{\sigma \gamma}{1+\sigma \gamma}}, N=\left(\frac{\varepsilon-1}{\varepsilon \psi}\right)^{\frac{1}{\gamma}} C^{-\frac{1}{\sigma \gamma}}, \\
& Y=N, \xi=C^{-\frac{1}{\sigma}}, Y^{f}=X_{Y} Y .
\end{aligned}
$$

\section{A.3 Log-linear Expansion of Equilibrium Conditions}

We log-linearize the equilibrium conditions about the steady state in which exports are at their normal level and inflation is zero. The complete markets condition, (37), implies

$$
\hat{q}_{t}=\frac{1}{\sigma} \hat{C}_{t}
$$

Log-linearizing (45), (46), and (6),

$$
\begin{aligned}
\hat{p}_{t}^{c} & =\frac{\omega_{c} q^{1-\eta_{c}}}{1-\omega_{c} q^{1-\eta_{c}}} \hat{q}_{t} \\
\hat{X}_{t} & =\eta_{f}\left(\hat{q}_{t}+\hat{p}_{t}^{c}\right)+\hat{Y}_{t}^{f}=\frac{\eta_{f}}{1-\omega_{c} q^{1-\eta_{c}}} \hat{q}_{t}+\hat{Y}_{t}^{f} \\
\hat{Y}_{t} & =\hat{N}_{t}
\end{aligned}
$$

where (51) makes use of (50) and (52) makes use of the log-linearization of (7). Log-linearizing (48) and making use of (50), (51) and (52) we obtain

$$
\begin{aligned}
\hat{N}_{t}= & \left(1-\omega_{c}\right)\left(p^{c}\right)^{\eta_{c}} C_{Y}\left(\frac{\eta_{c} \omega_{c} q^{1-\eta_{c}}}{1-\omega_{c} q^{1-\eta_{c}}} \hat{q}_{t}+\hat{C}_{t}\right) \\
& +X_{Y}\left(\frac{\eta_{f}}{1-\omega_{c} q^{1-\eta_{c}}} \hat{q}_{t}+\hat{Y}_{t}^{f}\right)
\end{aligned}
$$

where

$$
C_{Y} \equiv \frac{C}{Y}, X_{Y} \equiv \frac{X}{Y}
$$


Totally differentiating (47) and taking (50) into account,

$$
d \pi_{t}^{c}=d \pi_{t}+\frac{\omega_{c}\left(p^{c} q\right)^{1-\eta_{c}}}{\left[\left(1-\omega_{c}\right)+\omega_{c}\left(p^{c} q\right)^{1-\eta_{c}}\right]\left(1-\omega_{c} q^{1-\eta_{c}}\right)}\left(\hat{q}_{t}-\hat{q}_{t-1}\right) .
$$

Log-linearizing (7), (38), (39), and (40) about steady state implies

$$
d \pi_{t}=\kappa\left(\gamma \hat{N}_{t}+\hat{p}_{t}^{c}+\frac{1}{\sigma} \hat{C}_{t}\right)+\beta d \pi_{t+1}
$$

The object in square brackets in (55) is the log deviation of marginal cost, (41), from its steady state value. Substituting out for $\hat{N}_{t}$ using (53) and for $\hat{p}_{t}^{c}$ using (50) and after rearranging, we obtain

$$
d \pi_{t}=\kappa\left(\alpha_{C} \hat{C}_{t}+\gamma X_{Y} \hat{Y}_{t}^{f}\right)+\beta d \pi_{t+1}
$$

The log-linear approximation of (34) around steady state is:

$$
\hat{C}_{t}=-\sigma \delta\left(d R_{t}-d \pi_{t+1}\right)+\hat{C}_{t+1}
$$

where we use (54) and (49)

To compute the equilibrium, one finds $\hat{C}_{t}, d R_{t}$ and $d \pi_{t}$ that satisfy the monetary policy rule, (8), (9) and (10). The observation that the equilibrium for the small open economy may be approximated in this way.

\section{B Equilibrium when $\rho>0$}

Following Christiano (2002), to solve (9), (10) and (11) for $\hat{C}_{t}, d \pi_{t}$ and $d R_{t}$, define

$$
\mathbf{z}_{t}=\left(\begin{array}{c}
\hat{C}_{t} \\
d \pi_{t} \\
d R_{t}
\end{array}\right)
$$

and represent them in matrix form:

$$
\boldsymbol{\alpha}_{0} \mathbf{z}_{t+1}+\boldsymbol{\alpha}_{1} \mathbf{z}_{t}+\boldsymbol{\alpha}_{2} \mathbf{z}_{t-1}=\mathbf{0},
$$

where

$\boldsymbol{\alpha}_{0}=\left[\begin{array}{ccc}1 & \sigma \delta & 0 \\ 0 & 1 & 0 \\ 0 & (1-\rho) \alpha_{\pi} & 0\end{array}\right], \boldsymbol{\alpha}_{1}=\left[\begin{array}{ccc}-1 & 0 & -\sigma \delta \\ \kappa \alpha_{c} & -1 & 0 \\ (1-\rho) \alpha_{Y} \alpha_{N} & 0 & -1\end{array}\right], \boldsymbol{\alpha}_{2}=\left[\begin{array}{ccc}0 & 0 & 0 \\ 0 & 0 & 0 \\ 0 & 0 & \rho\end{array}\right]$ 
A solution to this system is a matrix, $\mathbf{A}$, where

$$
\mathbf{z}_{t}=\mathbf{A} \mathbf{z}_{t-1}
$$

having the properties that the eigenvalues of $\mathbf{A}$ are less than unity and,

$$
\boldsymbol{\alpha}_{0} \mathbf{A}^{2}+\boldsymbol{\alpha}_{1} \mathbf{A}+\boldsymbol{\alpha}_{2}=\left(\begin{array}{l}
0 \\
0 \\
0
\end{array}\right)
$$

When we solve this system, we verify that the $\mathbf{A}$ matrix with the required properties is unique. In addition, since the policy rate is the only endogenous state variable, we verify that only the last column of $\mathbf{A}$ has non-zero entries:

$$
\mathbf{A}=\left[\begin{array}{lll}
\mathbf{0} & \mathbf{0} & \mathbf{a}
\end{array}\right],
$$

where $\mathbf{a}$ is a $3 \times 1$ column vector. Let $\mathbf{z}^{*}$ denote the $3 \times 1$ vector of values taken on by the endogenous variables in the period that the system emerges from the zero bound:

$$
\mathbf{z}^{*}=\left(\begin{array}{c}
\hat{C}^{*} \\
\pi^{*} \\
R^{*}-r
\end{array}\right)=-\mathbf{a} r
$$

where the $*$ superscript indicates the period upon leaving the zero bound. Note that $z^{*}$ are independent of the endogenous variables under the zero bound. With $z^{*}$ in hand, we can compute the values taken on by the variables in the lower bound by solving (24) and (25).

\section{Dynamic Multiplier}

Following Christiano (2004), we solve this by recursive substitution for (29) and (30) to substitute out $d \pi_{t}$. With lag operator, (29) and (30) can be transformed into

$$
\begin{aligned}
d \pi_{t} & =\frac{\Gamma \hat{Y}_{t}+\Upsilon \hat{Y}_{t}^{f}}{1-\beta L^{-1}} \\
\hat{Y}_{t} & =\frac{\Phi L^{-1}}{1-L^{-1}}\left(d \pi_{t}+r\right)+X_{Y} \hat{Y}_{t}^{f} .
\end{aligned}
$$

Substituting our $d \pi_{t}$ from above two equations lead to

$$
\hat{Y}_{t}=h(L) \hat{Y}_{t}^{f}+\frac{(1-\beta) \Phi\left(1-\beta L^{-1}\right) L^{-1}}{\left(1-L^{-1}\right)\left(1-\beta L^{-1}\right)-\Phi L^{-1} \Gamma},
$$


where

$$
h(L)=\frac{\Phi \Upsilon L^{-1}+\left(1-L^{-1}\right)\left(1-\beta L^{-1}\right) X_{Y}}{\left(1-L^{-1}\right)\left(1-\beta L^{-1}\right)-\Phi \Gamma L^{-1}} .
$$

This could be expressed as

$$
h(L)=\frac{1}{X_{Y}} \frac{\left(1-\zeta_{1} L^{-1}\right)\left(1-\zeta_{2} L^{-1}\right)}{\left(1-\lambda_{1} L^{-1}\right)\left(1-\lambda_{2} L^{-1}\right)}
$$

where

$$
\begin{aligned}
\zeta_{1}+\zeta_{2} & =1+\beta-\frac{\Phi \Upsilon}{X_{Y}}, \zeta_{1} \zeta_{2}=\beta, \\
\lambda_{1}+\lambda_{2} & =1+\beta+\Phi \Gamma, \lambda_{1} \lambda_{2}=\beta,
\end{aligned}
$$

and set

$$
\lambda_{1}<\zeta_{1}<\beta, \lambda_{2}>\zeta_{2}>1 .
$$

As shown in Sargent (1987), Hamilton (1994) or Christiano (2004),

$$
\left(1-\zeta_{1} L^{-1}\right)\left(1-\zeta_{2} L^{-1}\right)=\zeta_{1} \zeta_{2}\left(\frac{1}{\zeta_{1}}-L^{-1}\right)\left(\frac{1}{\zeta_{2}}-L^{-1}\right)
$$

and

$$
\left(1-\lambda_{1} L^{-1}\right)^{-1}\left(1-\lambda_{2} L^{-1}\right)^{-1}=\left(\lambda_{1}-\lambda_{2}\right)^{-1}\left(\frac{\lambda_{1}}{1-\lambda_{1} L^{-1}}-\frac{\lambda_{2}}{1-\lambda_{2} L^{-1}}\right) .
$$

By multiplying them, $h(L)$ can be expressed after lengthy but straightforward algebra as

$$
\begin{aligned}
X_{Y} h(L)= & \frac{1+\left(\lambda_{1}-\zeta_{1}-\zeta_{2}\right) L^{-1}+\frac{\left(\lambda_{1}-\zeta_{2}\right)\left(\lambda_{1}-\zeta_{1}\right) L^{-2}}{1-\lambda_{1} L^{-1}}}{1-\frac{\lambda_{2}}{\lambda_{1}}} \\
& +\frac{1+\left(\lambda_{2}-\zeta_{1}-\zeta_{2}\right) L^{-1}+\frac{\left(\lambda_{2}-\zeta_{2}\right)\left(\lambda_{2}-\zeta_{1}\right) L^{-2}}{1-\lambda_{2} L^{-1}}}{1-\frac{\lambda_{1}}{\lambda_{2}}}
\end{aligned}
$$

As shown in (19), the aim here is to compute $h_{j}^{Y^{f}}$ as dynamic multipliers in

$$
X_{Y} h(L)=\sum_{j=1}^{\infty} h_{j}^{Y^{f}} L^{-(j-1)}
$$

From (56),

$$
h_{1}^{Y^{f}}=1, h_{2}^{Y^{f}}=\Phi\left(\Gamma+\frac{\Upsilon}{X_{Y}}\right) .
$$


Similarly, for $j \geq 3$,

$$
h_{j}^{Y^{f}}=\frac{\Phi\left(\Gamma+\frac{\Upsilon}{X_{Y}}\right)\left(\lambda_{1}^{j-1}-\lambda_{2}^{j-1}\right)}{\lambda_{1}-\lambda_{2}} .
$$

Therefore,

$$
X_{Y} h(L)=1+\Phi\left(\Gamma+\frac{\Upsilon}{X_{Y}}\right) L^{-1}+\frac{\Phi\left(\Gamma+\frac{\Upsilon}{X_{Y}}\right)}{\lambda_{1}-\lambda_{2}} \sum_{j=3}^{\infty}\left(\lambda_{1}^{j-1}-\lambda_{2}^{j-1}\right) L^{-(j-1)},
$$

If $\hat{Y}_{t}^{f}=1$ for $t=1, \ldots, T-1$, the export demand multiplier, $d Y^{l} / d Y^{f}$, becomes

$$
\frac{d Y^{l}}{d Y^{f}}=1+\Phi\left(\Gamma+\frac{\Upsilon}{X_{Y}}\right)+\frac{\Phi\left(\Gamma+\frac{\Upsilon}{X_{Y}}\right)}{\lambda_{2}-\lambda_{1}}\left(\lambda_{2}^{2} \frac{1-\lambda_{2}^{T-3}}{1-\lambda_{2}}-\lambda_{1}^{2} \frac{1-\lambda_{1}^{T-3}}{1-\lambda_{1}}\right),
$$

since

$$
\sum_{j=3}^{T-1}\left(\lambda_{1}^{j-1}-\lambda_{2}^{j-1}\right)=\lambda_{1}^{2} \frac{1-\lambda_{2}^{T-3}}{1-\lambda_{2}}-\lambda_{1}^{2} \frac{1-\lambda_{1}^{T-3}}{1-\lambda_{1}}
$$

where

$$
\lambda_{1}=\frac{1+\beta+\kappa \alpha_{C} \sigma \delta-\sqrt{\left(1+\beta+\kappa \alpha_{C} \sigma \delta\right)^{2}-4 \beta}}{2}, \lambda_{2}=\frac{\beta}{\lambda_{1}} .
$$

